\title{
Health \& Wealth: is weight loss success related to monetary savings in U.S. adults of low-income? Findings from a National Study
}

\author{
Kerem Shuval ${ }^{1,2^{*}}$ (D, Bob M. Fennis ${ }^{3,4}$, Qing Li ${ }^{1}$, Amir Grinstein ${ }^{5,6}$, Meike Morren ${ }^{6}$ and Jeffrey Drope ${ }^{1}$
}

\begin{abstract}
Background: Many individuals aspire to attain various goals in life, such as committing to a healthful diet to slim down or saving for retirement to enhance future welfare. While these behaviors (weight loss and saving) share the common denominator of self-regulation, it is unclear whether success in one domain is related to the other. Therefore, we examined the relationship between long term weight loss (LTWL) success and monetary savings among U.S. adults who at one point in life diverged from normal weight status.

Methods: Data on 1994 adults with a maximum BMI $\geq 25 \mathrm{~kg} / \mathrm{m}^{2}$ and with an annual household income equal or less than 200\% poverty level. Data were derived from a U.S. population-based study (NHANES). The independent variable was LTWL success (loss maintained for at least 1 year), which was operationalized as < 10\% (reference group), 10.00-19.99\%, and $\geq 20.00 \%$. The dependent variable was monetary savings (e.g., $401 \mathrm{~K}$ ), defined as a 3-category ordinal variable. We employed ordered logistic regression to estimate the relationship between LTWL success and increased odds for higher overall savings.

Results: Multivariable analysis revealed that adjusting for income, education and other covariates, being in the highest LTWL category ( $\geq 20.00 \%$ ) significantly reduced the likelihood of monetary savings in comparison to the reference group $(\mathrm{OR}=0.55,95 \% \mathrm{Cl}=0.34-0.91)$. This relationship was not observed in the lower LTWL category (10.00-19.99\%).

Conclusions: Adults who in the past were overweight or obese and who presently exhibit high levels of LTWL, were markedly less successful when it came to their finances. This might stem from significant cognitive-affective resources exerted during the weight loss process coupled with a paucity of financial resources which impede financial decision making. This supposition, however, warrants future research.
\end{abstract}

Keywords: Weight loss, Monetary savings, Self-regulation

\section{Background}

Despite New Year's resolutions to exercise and eat well to lose excess weight, most individuals are not able to follow through with their plan despite their best intentions [1]. In fact, only $\sim 20 \%$ of adults who are overweight successfully lose weight [2]. Indeed, more than two thirds of American adults are overweight or obese,

\footnotetext{
* Correspondence: kerem.shuval@gmail.com

${ }^{1}$ Economic and Health Policy Research Program, Department of Intramural

Research, American Cancer Society, Atlanta, GA, USA

${ }^{2}$ Faculty of Social Welfare \& Health Sciences, School of Public Health,

University of Haifa, Haifa, Israel

Full list of author information is available at the end of the article
}

which is mostly due to human behavior and environment, not genetics $[3,4]$. This situation incurs increased morbidity and soaring health care costs $[5,6]$. Similarly, while individuals are cognizant of the importance of saving for retirement, actual savings rates in the U.S. represent only $\sim 5 \%$ of disposable income [7]. Moreover, the median retirement savings account balance for the working-age American household is $\$ 3000$, and remains alarmingly low $(\$ 12,000)$ even for those nearing retirement age [8].

Both health and wealth outcomes require a selfregulatory effort in the form of goal setting, planning,

(c) The Author(s). 2019 Open Access This article is distributed under the terms of the Creative Commons Attribution 4.0 International License (http://creativecommons.org/licenses/by/4.0/), which permits unrestricted use, distribution, and reproduction in any medium, provided you give appropriate credit to the original author(s) and the source, provide a link to the Creative Commons license, and indicate if changes were made. The Creative Commons Public Domain Dedication waiver (http://creativecommons.org/publicdomain/zero/1.0/) applies to the data made available in this article, unless otherwise stated. 
overcoming hurdles and resisting immediate impulses [9, 10]. Goal setting (e.g., losing weight) and controlling emotions is required to preempt immediate gratification urges when temptation arises $[9,10]$. For example, when primed to eat chocolate cake an individual with a weight loss goal who has a high degree of self-regulation will likely opt for an apple rather than eating the cake to achieve their goal $[11,12] .$. In the psychological literature, while both constructs are frequently used interchangeably, self-regulation generally refers to intentional and deliberate actions by which individuals plan, monitor and alter their cognitions, emotions, and behaviors in the service of long term goals [13, 14]. Self-control, more specifically, refers to suppressing, overcoming or channeling acute impulses to the extent that they interfere with valued long term goals [14].

In economics, health and wealth decisions are viewed as inter-temporal decisions between myopic and farsighted choices [15]. That is, individuals with 'near sighted' (impatient) preferences will devalue future rewards (known as delayed discounting), such as future health benefits, over present day immediately gratifying choices (e.g., eating ice-cream) [11, 16-18]. Devaluing greater future benefits often occurs since the future rewards are not salient at present [19]. Individuals able to delay immediate gratifying behavior are regarded as having patient time preferences, which has been linked in the literature to less impulsive behavior [20]. Whereas traditional micro-economic theory regarded time preference as stable over time, more recent modeling integrates insights from psychology by acknowledging that time preferences could change over time, particularly when in a visceral state (e.g., when angry or hungry) [21-23]. For example, if one's goal is to adhere to a healthful diet yet social and environmental cues prime them to consume energy dense foods, their a priori goal will often not be met. This 'scenario', where the a priori goal is not met, is regarded as an inconsistent time preference and reflects a self-control problem [24].

Both fields (psychology and economics) concur that the ability to prioritize 'should' (e.g., walking on the treadmill) over 'want' (e.g., sitting on the couch watching TV) behaviors to achieve higher levels goals (e.g., chronic disease prevention), is indicative of higher levels of self-control or self-regulation $[25,26]$. Henceforth, in the current study we use the term 'self-regulation'. High self-regulation has been linked to behaviors that enhance health and well-being, such as educational attainment, monetary savings, and obesity prevention [27-30]. In the health domain, for example, a study by Stoklosa et al. (2018), among a national sample of U.S. adults, observed that higher self-regulation is linked to reduced obesity levels among adults and their children [21]. Moreover, Fan and Jin (2014) found that individuals who are obese exhibit lower levels of self-regulation than their normal weight counterparts, and that lower self-regulation is associated with unhealthful eating and physical inactivity [31]. In the specific case of self-regulation in financial decision making, research by Gubler and Pierce (2014) observed that employees who saved for retirement exhibited better blood test scores [32]. Similarly, Israel et al. (2014) found that higher credit scores, arguably indicative of financial prudence, were predictive of lower cardiovascular disease risk, irrespective of income [33].

The focal point of these studies, however, was on individuals with high self-regulation rather than the crossdomain behavior of those with lower levels. Furthermore, these studies have insufficiently focused on low-income individuals at increased risk for obesity and other chronic diseases, with less financial resources, and less access to medical care [34]. To this end, the current study focuses on weight loss and financial behaviors of low-income adults who were historically overweight. That is, at one point in life participants ceased maintaining normal weight status (henceforth, historically overweight). Thus, the present study aims to describe the relationship between long term weight loss (LTWL) success and monetary savings among adults who have been historically overweigh.

\section{Methods}

\section{Data and participants}

Data were derived from the National Health and Nutrition Examination Survey (NHANES); described elsewhere [35]. Briefly, NHANES is conducted on an ongoing basis bi-annually; the study design is crosssectional, and includes information on health, nutrition, and weight history [36]. In the current study we utilize 4 survey waves: 2007-8, 2009-10, 2011-12, 2013-14. These waves represent observations at one-time point; that is, they are not longitudinal in nature. A total of 7172 adults aged $22-59$ years who were not underweight $\left(\mathrm{BMI}<18.5 \mathrm{~kg} / \mathrm{m}^{2}\right)$, not pregnant and not told by their physician that they have a heart disease or stroke were considered for inclusion after meeting the following criteria: historically overweight (i.e., maximum BMI of $\geq 25$ $\mathrm{kg} / \mathrm{m}^{2}$ ), [37] able to work, with no physical/mental limitations, or cognitive impairment. Of these, 5178 observations were omitted due to incomplete information on the primary independent variable (LTWL), dependent variable (monetary savings), and covariates (as described below). This resulted in an analytic dataset of 1994 participants.

This study sample consisted of low-income participants since only those reporting a family annual income of equal or less than $200 \%$ poverty level were asked to respond to questions pertaining to their monetary savings [36]. Thus, the present study sample 
( $n=1994)$ differs from the omitted observations $(n=$ 5178 ) both in socio-demographic characteristics and health status. For example, in comparison to the omitted sample not meeting inclusion criteria, the present study sample had a markedly lower income, (e.g., $31.6 \%$ vs. $4.0 \%$ had an annual household income of less than $\$ 20,000)$, was less educated $(14.4 \%$ vs. $37.2 \%$ with a college education), and fewer reported being in excellent health $(8.4 \%$ vs. $12.2 \%)$. Hence the present study sample is not representative of all NHANES participants. In addition, it should be noted that NHANES obtained informed consent from participants and received ethics approval from the National Center for Health Statistics Research Ethics Review Board. The current study received exempt status from the Morehouse School of Medicine Institutional Review Board.

\section{Primary independent and dependent variable}

The primary independent variable was LTWL, which was based on reported maximum weight, weight 1 year ago, and the present weight [37]. More specifically, LTWL (i.e., loss maintained for at least 1 year) was computed by subtracting either the current or the weight 1 year ago (the highest of the two) from participants' maximum weight. This was then divided by the current weight and multiplied by 100 . This is based on the approach taken by Kraschnewski (2010) and Knell (2018) $[37,38]$. The LTWL percentage was grouped into the following 5 categories in adherence with previous research: $0.0-4.9 \%$ (reference group), 5.0-9.9\%, 10.0$14.9 \%, 15.0-19.9 \%$, and $\geq 20.0 \%$ [37, 38]. To avoid sparse cells, [39] we then grouped this variable into 3 clinically meaningful categories: 0.0-9.9\% (reference group), 10.0$19.9 \%$, and $\geq 20.0 \%$. The $10 \%$ cutoff was selected since the evidence indicates that losing $10 \%$ or more of one's maximum body weight (and maintaining it over time) is related with a significant reduction in chronic morbidity risk $[2,37,40]$. Grouping this variable into 5 or 3 categories did not change results materially in multivariable analysis.

The primary dependent variable was total savings, an ordinal variable based on two questions. In the first question, participants reported if they (or a household member) currently have more than $\$ 5000$ in savings in all accounts including cash, savings/checking, stock, mutual funds, and retirement (e.g., $401 \mathrm{~K}$ ) [36]. If they responded affirmatively then they were not asked the second question. If they indicated less than $\$ 5000$ in savings, they were asked to select one of the following categories: $<\$ 500$, \$501-\$1000, \$1001-\$2000, \$2001-\$3000, \$3001-\$4000, and $\$ 4001-\$ 5000$. From these two questions a 3-category saving variable was created $(<\$ 500, \$ 501-\$ 5000,>\$ 5000)$. We utilized a 3 group categorization for the saving variable rather than the original categories to avoid sparse cells [39]; though results did not change materially using either approach.

\section{Covariates}

The following variables were considered as potential confounders in line with previous research: [37, 38] college graduate (yes/no), annual household income $(<\$ 20,000$; $\$ 20,000-\$ 44,999, \$ 45,000-\$ 74,999, \geq \$ 75,000)$, and having a diet goal (yes/no). That is, participants who responded positively to one or more of the following three questions were regarded as having a diet goal: (1) Was their weight change in the past year intentional; (2) Did they try to lose weight in the past year; and (3) Did they take action to prevent weight gain in the past year. Conversely, those responding negatively to all three questions were defined as not having a diet goal. Additionally, the following covariates were adjusted for the analysis: self-reported health status (fair, good, very good, excellent), current smoking (3.08 ng/ $\mathrm{mL}$ cotinine cutoff), [41] gender, age, race/ethnicity (Hispanic, non-Hispanic black, non-Hispanic white, other), marital status (married, divorced/separated, widowed, never married), and household size.

\section{Statistical analysis}

The relationship between LTWL (primary independent variable), to monetary savings (dependent variable) was estimated using multivariable ordered logistic regression while adjusting for covariates (age, race/ethnicity, gender, annual household income, household size, marital status, college education, self-reported health status, current smoking, and having a diet goal) based on prior research [37, 38]. Ordered regression was utilized due to the ordinal nature of the saving variable, where higher categories indicate increased odds for more savings [42, 43]. Results from the model are presented as adjusted odds ratios (OR) and their 95\% confidence intervals (CI) for a transition to a higher saving group versus remaining in the same category. Due to the complex multistage random sampling of NHANES, weight procedures were used [44]. More specifically, the mobile exam weights (provided by NHANES) of each of the survey waves (2007-9, 2009-10, 2011-12, 2013-14) were combined and divided by 4 to represent 8 year weights [44]. STATA 13.1 (Stata-Corp LP) was used in all statistical analyses. The threshold for statistical significance was set at $\alpha<0.05$.

\section{Results}

The socio-demographic characteristics (weighted) of the study sample are presented in Table 1 . Briefly, the mean age of participants was 36.5 years $(\mathrm{SE}=0.35)$, and $48.6 \%$ were women. Slightly less than half $(48.5 \%)$ were non- 
Table 1 Descriptive Characteristics (Weighted) of Sample: NHANES 2007-2014 $(n=1994)$

\begin{tabular}{|c|c|c|}
\hline Characteristics & Weighted \% & SE \\
\hline \multicolumn{3}{|l|}{ Gender } \\
\hline Women & $48.65 \%$ & 0.01 \\
\hline Age (years): mean (SE) & 36.50 & 0.35 \\
\hline \multicolumn{3}{|l|}{ Race/Ethnicity } \\
\hline Non-Hispanic White & $48.54 \%$ & 0.03 \\
\hline Non-Hispanic Black & $17.38 \%$ & 0.02 \\
\hline Hispanic & $28.41 \%$ & 0.02 \\
\hline Other & $5.67 \%$ & 0.01 \\
\hline \multicolumn{3}{|l|}{ Marital Status } \\
\hline Married & $43.32 \%$ & 0.02 \\
\hline Widow & $0.91 \%$ & 0.00 \\
\hline Divorced/Separated & $16.07 \%$ & 0.01 \\
\hline Never married & $25.69 \%$ & 0.02 \\
\hline College Graduate & $14.45 \%$ & 0.01 \\
\hline Household Size: mean (SE) & 3.803 & 0.05 \\
\hline \multicolumn{3}{|l|}{ Annual Household Income (U.S. Dollars)- categories } \\
\hline$<\$ 20,000.00$ & $31.62 \%$ & 0.01 \\
\hline$\$ 20,000.00-\$ 44,999.00$ & $53.00 \%$ & 0.01 \\
\hline$\$ 45,000.00-\$ 74,999.00$ & $9.78 \%$ & 0.01 \\
\hline$\geq \$ 75,000.00$ & $5.60 \%$ & 0.01 \\
\hline Long-term Weight Loss Maintenance (0.00-9.99\%) & $71.85 \%$ & 0.01 \\
\hline Long-term Weight Loss Maintenance (10.00-19.99\%) & $20.34 \%$ & 0.01 \\
\hline Long-term Weight Loss Maintenance ( $\geq 20.00 \%)$ & $7.81 \%$ & 0.01 \\
\hline \multicolumn{3}{|l|}{ Self-reported Health Status } \\
\hline Excellent & $8.47 \%$ & 0.01 \\
\hline Very good & $27.74 \%$ & 0.01 \\
\hline Good & $44.73 \%$ & 0.01 \\
\hline Fair & $17.33 \%$ & 0.01 \\
\hline Poor & $1.72 \%$ & 0.00 \\
\hline Current Smoker & $40.30 \%$ & 0.02 \\
\hline Diet Goal & $56.44 \%$ & 0.01 \\
\hline \multicolumn{3}{|l|}{ Total Savings (U.S. Dollars) } \\
\hline$<\$ 500.00$ & $72.61 \%$ & 0.02 \\
\hline$\$ 501.00-\$ 5000.00$ & $13.12 \%$ & 0.01 \\
\hline$>\$ 5000.00$ & $14.28 \%$ & 0.02 \\
\hline
\end{tabular}

NHANES National Health and Nutrition Examination Survey, SE standard error, NHANES weights were utilized

Hispanic whites, $28.4 \%$ were Hispanic, and $17.4 \%$ were non-Hispanic black. Furthermore, $14.4 \%$ were college graduates, and $84.6 \%$ had an annual household income of less than $\$ 45,000$.

Multivariable analysis, presented in Table 2, reveals that in comparison to the reference group $(<10 \% \mathrm{LTWL})$, a significant inverse relationship was found between the $\geq 20 \%$
Table 2 Long-term Weight Loss and Monetary Savings: ordered logistic regression ${ }^{\mathrm{a}}$

\begin{tabular}{|c|c|}
\hline & $\begin{array}{l}\text { Total Savings }{ }^{\mathrm{a}} \\
\text { OR } \\
95 \% \mathrm{Cl}\end{array}$ \\
\hline \multicolumn{2}{|c|}{ Long-term Weight Loss-categories ( $<10 \%$ reference) } \\
\hline 10.00-19.99\% Weight Loss & $\begin{array}{l}0.92 \\
0.69-1.23\end{array}$ \\
\hline$\geq 20.00 \%$ Weight Loss & $\begin{array}{l}0.55^{*} \\
0.34-0.91\end{array}$ \\
\hline Diet Goal & $\begin{array}{l}1.46^{*} \\
1.13-1.90\end{array}$ \\
\hline College Graduate & $\begin{array}{l}2.95^{*} \\
1.89-4.60\end{array}$ \\
\hline \multicolumn{2}{|c|}{ Annual Household Income $(<\$ 20,000$ reference) } \\
\hline$\$ 20,000.00-\$ 44,999.00$ & $\begin{array}{l}1.42 \\
0.99-2.12\end{array}$ \\
\hline$\$ 45,000.00-\$ 74,999.00$ & $\begin{array}{l}3.04^{*} \\
1.88-4.91\end{array}$ \\
\hline$\$ \geq 75,000.00$ & $\begin{array}{l}6.22^{*} \\
2.84-13.61\end{array}$ \\
\hline
\end{tabular}

$\mathrm{Cl}$ confidence intervals, $O R$ odds ratio. An *indicates statistical significance at the $p<0.05$ level

${ }^{a}$ The multivariable regression model adjusted for age, race/ethnicity, gender, household size, marital status, self-reported health status, and current smoking; NHANES weights were utilized. Ordered logistic regression was used due to the ordinal nature of the dependent variable

LTWL category and total savings. That is, individuals in the highest LTWL category were $45 \%$ less likely to save $(95 \% \mathrm{CI}=0.34-0.91)$ than the reference group. This relationship was not observed for the lower, 10-19.99\% LTWL category (OR $=0.92 ; 95 \%$ CI $0.69-1.23)$. In addition, having a diet goal, college graduation, and a higher annual income were each independently and positively related to increased savings. Specifically, participants with a diet goal were 1.46 times more likely to save (95\%CI 1.13-1.90), college graduates were 2.95 times more likely to save $(95 \% \mathrm{CI} 1.89-4.60)$, and those in the highest income strata were 6.22 times more likely to save $(95 \%$ CI $2.84-13.61)$.

\section{Discussion}

The inverse relationship observed between LTWL and monetary savings might stem from the fact that in this study sample participants were historically overweight, which could indicate lower overall self-regulation $[45,46]$. Thus, unlike individuals with high self-regulation who are able to control their thoughts, goals and behaviors across domains, [47] those with lower levels might be able to exert self-control in some domains but not in others. This finding might be explained by the significant cognitiveaffective effort exerted by the group in the process of losing $20 \%$ (or more) of their maximum weight, [12] which did not leave enough "mental resources" deployed when it came to financial decision-making. This might also be compounded by the fact that low-income participants 
experience a preponderance of adverse life events, which assail mental resources and detrimentally affect decisionmaking [48-50]. Theses suppositions are preliminary, however, and should be substantiated in study samples which contain additional information pertaining to adverse life events, psychological mechanisms, social and environmental variables, as well as more elaborate data pertaining to spending and saving behaviors.

Nonetheless, these findings are novel and important since they illustrate how decisions in different domains are interrelated. These decisions, namely to lose weight and save money, have paramount health and welfare implications. The field of public health has traditionally focused on social determinants of health, that is, how one's socio-demographic and economic status affects health [51]. Evidence clearly points to the fact that individuals with low-incomes have higher prevalence rates of obesity, type 2 diabetes, cardiovascular diseases, and premature death, while having less access to quality medical care in comparison to their higher income counterparts [52-54]. The increased risk for chronic morbidity and mortality among individuals with low incomes likely stems from a higher rate of 'behavioral risk factors', such as physical inactivity and unhealthful eating leading to obesity, which is due to living in environments conducive to these behaviors [55]. Research, however, has rarely assessed whether health behaviors are related to monetary savings, both sharing a common underlying factor of self-regulation.

It should be noted that as with the Gubler and Pierce (2014) study, a direct measure of self-regulation was not available in the present study. However, analysis reveals that individuals possessing a diet goal were significantly more likely to save money. While a diet goal leads to goal directed action in the eating domain, [12] it also might be related to achieving higher level goals in other domains. Hence, having a diet goal might be a proxy for higher overall self-regulation versus lower self-regulation among those without a diet goal in this sample [35, 41-43]. This assumption, however, needs to be substantiated in future research. Additionally, the NHANES dataset is cross-sectional, which precludes determining a temporal relationship. Moreover, whereas LTWL is based on an individual's weight at three time points, the exact timeframe in which the financial savings occurred is not clear. Further, the monetary saving behavior was based on either individual or household savings, which does not necessarily reflect an individual's decision alone. Additionally, the monetary saving variable cannot be expressed as a percent of total income due the way this variable and the annual house income variable are constructed in the survey. Nonetheless, annual household income is adjusted for in multivariable analysis.
While we adjusted for self-reported health status and excluded participants who were underweight (as a proxy for underlying medical conditions) and with heart disease and stroke, it could still be possible that weight loss occurred as a result of a medical condition. Finally, examining decision making in low-income samples has important health, welfare and policy implications, yet the analytic sample utilized in this study is not representative of the U.S. population at large.

\section{Conclusions}

The present study contributes to the literature by examining the cross-domain behavior of adults, especially from low-income families, exhibiting various levels of LTWL success. More specifically, scant evidence exists focusing on decision-making in the health and financial domain of adults who have been historically overweight and predominately low-income. Thus, it is crucial to find strategies to improve the health and financial decision making of this population, who likely have lower levels of self-regulation [31]. This is particularly important in modern society which encourages consumption of palatable foods (i.e., 'obesogenic environment') and goods through social and environment cues [45]. Current study findings indicate that behaviors in two different domains that share the common mechanism of self-regulation are inversely related in this sample. That is, those who achieved the greatest weight loss were significantly less likely to save money. Hence, it might be advisable to address both health behaviors and financial decision making jointly to enhance individuals' future health and welfare. This finding, however, warrants further longitudinal research in additional samples containing more information pertaining to underlying psychological mechanisms as well as financial behavior.

\section{Abbreviations}

BMI: Body mass index; Cl: Confidence interval; LTWL: Long term weight loss; NHANES: National Health and Nutrition Examination Survey; OR: Odds ratio; SE: Standard error

\section{Acknowledgements}

None.

\section{Authors' contributions}

KS contributed to the study conception, design, analytic approach, interpretation of results, led the writing of the manuscript, and critical revision of various drafts. QL contributed to the study conception, design, analytic approach, statistical analysis, interpretation of results, and critical revision of various drafts. BF, JD, AG, and MM contributed to the study design, analytic approach, interpretation of results, and critical revision of various drafts. All authors have read and approved the manuscript.

\section{Funding}

The current study did not receive funding.

\section{Availability of data and materials}

The data used for this study is from NHANES, which is publicly available. Data can be downloaded from the U.S. Centers for Disease Control and Prevention website: https://wwwn.cdc.gov/nchs/nhanes/ 


\section{Ethics approval and consent to participate}

The NHANES received ethics approval from the National Center for Health Statistics Research Ethics Review Board. The current study received exempt status from Morehouse School of Medicine Institutional Review Board since the data used for the study is publically available and de-identified.

\section{Consent for publication}

Not applicable.

\section{Competing interests}

The Authors declare that there are no competing interests.

\section{Author details}

'Economic and Health Policy Research Program, Department of Intramural Research, American Cancer Society, Atlanta, GA, USA. ${ }^{2}$ Faculty of Social Welfare \& Health Sciences, School of Public Health, University of Haifa, Haifa, Israel. ${ }^{3}$ Department of Marketing, University of Groningen, Groningen, The Netherlands. ${ }^{4}$ School of Marketing and International Business, Victoria University of Wellington, Wellington, New Zealand. ${ }^{5}$ 'Amore-McKim School of Business, Northeastern University, Boston, MA, USA. ${ }^{6}$ Faculty of Economics and Business Administration, Vrije Universiteit Amsterdam, Amsterdam, The Netherlands.

Received: 16 September 2019 Accepted: 30 September 2019

\section{Published online: 21 November 2019}

\section{References}

1. Dhami S. The foundations of behavioral economic analysis. New York and Glasgow: Oxford University Press; 2016.

2. Wing RR, Phelan S. Long-term weight loss maintenance. Am J Clin Nutr. 2005;82(1 Suppl):222S-5S.

3. Hales CM, Fryar CD, Carroll MD, Freedman DS, Ogden CL. Trends in obesity and severe obesity prevalence in US youth and adults by sex and age, 20072008 to 2015-2016. JAMA. 2018. https://doi.org/10.1001/jama.2018.3060.

4. Katz DL. Perspective: obesity is not a disease. Nature. 2014;508:S57.

5. Finkelstein EA, Khavjou OA, Thompson H, Trogdon JG, Pan L, Sherry B. Obesity and severe obesity forecasts through 2030. Am J Prev Med. 2012:42:563-70.

6. World Health Organization. Obesity and overweight. Obesity and Overweight Fact Sheet. 2017. http://www.who.int/mediacentre/factsheets/ fs311/en/. Accessed 23 Dec 2017.

7. Knoll M. The role of behavioral economics and behavioral decision making in Americans' retirement savings decisions. Soc Secur Bull. 2010;70 https:/www. ssa.gov/policy/docs/ssb/v70n4/v70n4p1.html\#mn9. Accessed 23 Dec 2017.

8. Rhee $\mathrm{N}$. The retirement savings crisis: is it worse than we think? Washington DC; 2013. https://www.nirsonline.org/reports/the-retirement-savings-crisis-isit-worse-than-we-think/. Accessed 13 Oct 2019

9. Koch AK, Nafziger J. Self-regulation through goal setting*. Scand J Econ. 2011;113:212-27.

10. Mann T, de Ridder D, Fujita K. Self-regulation of health behavior: social psychological approaches to goal setting and goal striving. Health Psychol. 2013;32:487-98.

11. Shuval K, Stoklosa M, Pachucki MC, Yaroch AL, Drope J, Harding M. Economic preferences and fast food consumption in US adults: insights from behavioral economics. Prev Med. 2016;93:204-10.

12. Stroebe W, van Koningsbruggen GM, Papies EK, Aarts H. Why most dieters fail but some succeed: a goal conflict model of eating behavior. Psychol Rev. 2013;120:110-38.

13. Baumeister RF, Vohs KD. Encyclopedia of social psychology. Los Angeles, London, New Delhi, Singapore: Sage; 2007.

14. de Ridder D, Adriaanse M, Fujita K. Routledge international handbook of selfcontrol in health and well-being. 1st ed. London: Routledge; 2017. https:// www.taylorfrancis.com/books/e/9781315648576. Accessed 15 Sept 2019

15. Ericson KM, Laibson D. Intertemporal choice. In: Bernheim BD, DellaVigna S, Laibson D, editors. Handbook of Behavioral Economics: Applications and Foundations 1. North-Holland; 2019. p. 1-67. doi:https://doi.org/10.1016/bs. hesbe.2018.12.001

16. Shuval K, Leonard T, Drope J, Katz DL, Patel AV, Maitin-Shepard M, et al. Physical activity counseling in primary care: insights from public health and behavioral economics. CA Cancer J Clin. 2017;67:233-44.
17. Odum AL. Delay discounting: I'm a k, You're a k. J Exp Anal Behav. 2011;96: 427-39.

18. Loewenstein G, Brennan T, Volpp KG. Asymmetric paternalism to improve health behaviors. JAMA. 2007;298:2415-7.

19. Leonard T, Shuval K. Behavioral economic tools for promotion of physical activity. In: Behavioral economics and healthy behaviors: key concepts and current research. New York: Routledge/Taylor \& Francis Group; 2017. p. 70-89.

20. Madden GJ, Bickel WK. Impulsivity: the behavioral and neurological science of discounting. Washington DC: American Psychological Association; 2010.

21. Stoklosa M, Shuval K, Drope J, Tchernis R, Pachucki M, Yaroch A, et al. The intergenerational transmission of obesity: the role of time preferences and self-control. Econ Hum Biol. 2018;28:92-106.

22. Laibson D. Golden eggs and hyperbolic discounting. Q J Econ. 1997;1 12:443-78.

23. Loewenstein G. Hot-cold empathy gaps and medical decision making. Health Psychol. 2005;24:S49.

24. Delaney L, Lades LK. Present Bias and everyday self-control failures: a day reconstruction study. Behav Decis Mak. 2017;30:1157-67.

25. Milkman KL, Rogers T, Bazerman MH. Harnessing our inner angels and demons: what we have learned about want/should conflicts and how that knowledge can help us reduce short-sighted decision making. Perspect Psychol Sci. 2008:3:324-38.

26. Leonard T, Shuval K, de Oliveira A, Skinner CS, Eckel C, Murdoch JC. Health behavior and behavioral economics: economic preferences and physical activity stages of change in a low-income African-American community. Am J Health Promot. 2013;27:211-21.

27. de Ridder DTD, Lensvelt-Mulders G, Finkenauer C, Stok FM, Baumeister RF. Taking stock of self-control: a meta-analysis of how trait self-control relates to a wide range of behaviors. Personal Soc Psychol Rev. 2011;16:76-99.

28. Mischel W. Self-control theory. In: Handbook of theories of social psychology: volume 2. London: SAGE Publications Ltd; 2012. p. 1-22. https://doi.org/10.4135/9781446249222.

29. Sutter M, Kocher MG, Glätzle-Rüetzler D, Trautmann ST. Impatience and uncertainty: experimental decisions predict adolescents' field behavior. Am Econ Rev. 2013;103:510-31.

30. Bradford D, Courtemanche C, Heutel G, McAlvanah P, Ruhm C. Time preferences and consumer behavior. J Risk Uncertain. 2017:55:119-45.

31. Fan M, Jin Y. Obesity and self-control: food consumption, physical activity, and weight-loss intention. Appl Econ Perspect Policy. 2014;36:125-45.

32. Gubler T, Pierce L. Healthy, wealthy, and wise: retirement planning predicts employee health improvements. Psychol Sci. 2014;25:1822-30.

33. Israel S, Caspi A, Belsky DW, Harrington H, Hogan S, Houts R, et al. Credit scores, cardiovascular disease risk, and human capital. Proc Natl Acad Sci U S A. 2014;111:17087-92.

34. de Oliveira AC, Leonard TC, Shuval K, Skinner CS, Eckel C, Murdoch JC. Economic preferences and obesity among a low-income African American community. J Econ Behav Organ. 2016;131:196-208.

35. Centers for Disease Control and Prevention. NHANES. https://www.cdc.gov/ nchs/nhanes/index.htm. Accessed 9 Jan 2017.

36. NHANES: Income Data Documentation, Codebook, and Frequencies. National Health and Nutrition Examination Survey 2011-2012 Data Documentation, Codebook, and Frequencies. 2012. https://wwwn.cdc.gov/ Nchs/Nhanes/2011-2012/INQ_G.htm\#INQ140. Accessed 16 July 2018.

37. Kraschnewski JL, Boan J, Esposito J, Sherwood NE, Lehman EB, Kephart DK, et al. Long-term weight loss maintenance in the United States. Int J Obes. 2010;34:1644-54.

38. Knell G, Li Q, Pettee Gabriel K, Shuval K. Long-term weight loss and metabolic health in adults concerned with maintaining or losing weight: findings from NHANES. Mayo Clin Proc. 2018;93:1611-6.

39. Greenland S, Schwartzbaum JA, Finkle WD. Problems due to small samples and sparse data in conditional logistic regression analysis. Am J Epidemiol. 2000;151:531-9.

40. Wing RR, Lang W, Wadden TA, Safford M, Knowler WC, Bertoni AG, et al. Benefits of modest weight loss in improving cardiovascular risk factors in overweight and obese individuals with type 2 diabetes. Diabetes Care. 2011; 34:1481-6.

41. Benowitz NL, Bernert JT, Caraballo RS, Holiday DB, Wang J. Optimal serum cotinine levels for distinguishing cigarette smokers and nonsmokers within different racial/ethnic groups in the United States between 1999 and 2004. Am J Epidemiol. 2009;169:236-48.

42. Shuval K, Gabriel KP, Leonard T. TV viewing and BMl by race/ethnicity and socio-economic status. PLoS One. 2013;8:e63579. 
43. Williams R. Generalized ordered logit/partial proportional odds models for ordinal dependent variables. Stata J. 2006;6:58.

44. Nguyen BT, Ford CN, Yaroch AL, Shuval K, Drope J. Food security and weight status in children: interactions with food assistance programs. Am J Prev Med. 2017;52:S138-44.

45. Johnson F, Pratt $M$, Wardle J. Dietary restraint and self-regulation in eating behavior. Int J Obes. 2012;36:665-74.

46. van Dellen MR, Hoyle RH, Miller R. The Regulatory Easy Street: SelfRegulation Below the Self-Control Threshold Does not Consume Regulatory Resources. Pers Individ Differ. 2012;52:898-902.

47. Castillo M, Ferraro PJ, Jordan JL, Petrie R. The today and tomorrow of kids: time preferences and educational outcomes of children. J Public Econ 2011;95:1377-85.

48. Public Interest Goverment Relations Office. The Psychology of Scarcity: How Limited Resources Affect Our Decisions And Behaviors; 2016. https://doi.org/ 10.1037/e509892016-001.

49. Shah AK, Mullainathan S, Shafir E. Some consequences of having too little. Science. 2012;338:682-5.

50. Proper KI, Picavet HSJ, Bogers RP, Verschuren WM, Bemelmans WJ. The association between adverse life events and body weight change: results of a prospective cohort study. BMC Public Health. 2013;13:957.

51. Satcher D. Include a social determinants of health approach to reduce health inequities. Public Health Rep. 2010;125(Suppl 4):6-7.

52. Harvey JR, Ogden DE. Obesity treatment in disadvantaged population groups: where do we stand and what can we do? Prev Med. 2014;68:71-5.

53. Siddiqi Z, Tiro JA, Shuval K. Understanding impediments and enablers to physical activity among African American adults: a systematic review of qualitative studies. Health Educ Res. 2011;26:1010-24.

54. Chetty R, Stepner M, Abraham S, Lin S, Scuderi B, Turner N, et al. The association between income and life expectancy in the United States, 2001 2014. JAMA. 2016;315:1750-66.

55. Khullar D. Health, income, \& poverty: where we are \& what could help. 2018. https://www.healthaffairs.org/do/10.1377/hpb20180817.901935/full/.

\section{Publisher's Note}

Springer Nature remains neutral with regard to jurisdictional claims in published maps and institutional affiliations.

Ready to submit your research? Choose BMC and benefit from:

- fast, convenient online submission

- thorough peer review by experienced researchers in your field

- rapid publication on acceptance

- support for research data, including large and complex data types

- gold Open Access which fosters wider collaboration and increased citations

- maximum visibility for your research: over $100 \mathrm{M}$ website views per year

At $\mathrm{BMC}$, research is always in progress.

Learn more biomedcentral.com/submissions 